\title{
Small-bore wire-guided chest drains: Safety, tolerability, and effectiveness in pneumothorax, malignant effusions, and pleural empyema
}

\author{
Stefano Cafarotti, MD, ${ }^{\text {a } V a l e n t i n a ~ D a l l ' ~ A r m i, ~ M D, ~}{ }^{\mathrm{b}}$ Giacomo Cusumano, MD, ${ }^{\mathrm{a}}$ Stefano Margaritora, $\mathrm{PhD},{ }^{\mathrm{a}}$ \\ Elisa Meacci, MD, ${ }^{\mathrm{a}}$ F. Lococo, MD, ${ }^{\mathrm{a}}$ M. L. Vita, MD, ${ }^{\mathrm{a}}$ V. Porziella, MD, ${ }^{\mathrm{a}} \mathrm{S}$. Bonassi, MD, \\ Alfredo Cesario, MD, ${ }^{\mathrm{a}, \mathrm{c}}$ and Pierluigi Granone, $\mathrm{PhD}^{\mathrm{a}}$
}

\begin{abstract}
Background: The use of small-bore wire-guided chest drains for pleural effusions and pneumothorax has become popular; however, limited data are available on its efficacy and morbidity. The aim of this retrospective study is to measure, via the analysis of the so far largest reported cohort, the efficacy, safety, and tolerability of this approach in different clinical conditions.
\end{abstract}

\begin{abstract}
Methods: In the period from January 2002 to December 2008, 1092 patients have undergone the positioning of a small-bore wire-guided chest drain (12F) for the evidence of pneumothorax or pleural effusion and have been monitored over time for morbidity, pain at the time of insertion (measured via the visual analogue scale), and drain failure for misplacement or blockage. Patients with trauma were excluded from this study.
\end{abstract}

\begin{abstract}
Results: Male/female ratio and mean age were respectively $418: 674$ and $55.85 \pm 18.6$. Three-hundred ninetynine $(36.5 \%)$ drains were inserted for pneumothorax, 324 (29.7\%) for malignant effusion, $97(8.9 \%)$ for empyema, and $272(24.9 \%)$ for nonmalignant effusion. The pain experience was on average "very mild" (mean visual analogue scale $=4.6 \mathrm{~mm}$ ). The overall drain failure rate was $12.9 \%$. The percentage of successful cases was $93.8 \%$ in malignant effusion, $93 \%$ in pneumothorax, and $92.3 \%$ in nonmalignant effusion; in the cases of pathologically diagnosed empyema, drains were more likely to get blocked $(74.2 \%)$. We recorded 1 serious complication within the malignant effusion group.
\end{abstract}

Conclusions: Wire-guided 12F Seldinger-type drains are a well-tolerated and effective method of treating pneumothorax and uncomplicated pleural effusions (malignant and nonmalignant) with acceptable morbidity. The use of 12F small-bore chest drain is not indicated for the treatment of empyema. (J Thorac Cardiovasc Surg 2011;141:683-7)

The most appropriate size of the chest tube for drainage of pneumothorax (PNX), pleural effusion, and empyema is still a forum of open discussion among thoracic surgeons and pneumologists. In fact, although positioning of the small-bore wire-guided chest drain is definitely less traumatic and less uncomfortable for the patients than that of the large-bore type, the effectiveness of these drains in pleural effusion and in empyema has not yet been validated in sufficiently large clinical series.

To the best of our knowledge, and as recently reviewed by the British Thoracic Society, ${ }^{1,2}$ there are only few studies reporting relatively large series. ${ }^{3,4}$ Our everyday clinical experience brought us to appreciate the beneficial effects

\footnotetext{
From the Division of General Thoracic Surgery, ${ }^{\mathrm{a}}$ Catholic University; Unit of Clinical and Molecular Epidemiology, ${ }^{\mathrm{b}}$ IRCCS San Raffaele Pisana; and CdC San Raffaele Velletri, ${ }^{\mathrm{c}}$ Rome, Italy.

Disclosures: Authors have nothing to disclose with regard to commercial support.

Received for publication Jan 14, 2010; revisions received July 19, 2010; accepted for publication Aug 15, 2010; available ahead of print Oct 14, 2010.

Address for reprints: Giacomo Cusumano, MD, Division of General Thoracic Surgery, Catholic University, Rome, Italy, Largo F. Vito 1, Rome, Italy 00168 (E-mail: giacomare55@hotmail.com).

$0022-5223 / \$ 36.00$

Copyright (c) 2011 by The American Association for Thoracic Surgery doi:10.1016/j.jtcvs.2010.08.044
}

of the use of small-bore wire-guided chest drains, which we have routinely been using over the past 10 years for the treatment of nonmalignant and malignant pleural effusions (NME/ME) and PNX. Aware of the limits of a retrospective analysis, however, we think that our findings stemming from the investigation of the evidence on a large cohort can importantly contribute to the discussion on the indication for small-bore chest drain insertion and provide definitive figures to exclude patients with pleural empyema from this procedure.

\section{METHODS AND PATIENTS}

This retrospective observational study involved 1092 patients with clinical and radiologic evidence of PNX or ME/NME consecutively treated with drainage via a small-bore wire-guided drain in a period of 7 years (January 2002 to December 2008). Our selection policy was to treat each patient who had PNX, NME/ME, or empyema with a small-bore drain. A communication to the institutional review board was issued and a coherent written informed consent was implemented and obtained from all patients before each procedure. Patients who required surgical placement of a chest drain for thoracic surgery, evidence of thoracic trauma (hemothorax), and empyema were excluded from this approach. These were treated with the positioning of larger tubes $(24 \mathrm{~F}-32 \mathrm{~F}$, bore size requirements evaluated on a case-by-case basis), with radiologic guidance of the tube insertion, or with a videothoracoscopic surgical approach, where appropriate. The empyema cases recorded in this study consist of subjects in whom the 


\section{Abbreviations and Acronyms \\ $\mathrm{ME}=$ malignant pleural effusion \\ $\mathrm{NME}=$ nonmalignant pleural effusion \\ PNX = pneumothorax \\ VAS $=$ visual analogue scale}

diagnosis of empyema was made pathologically with chemical analysis of the fluid that was radiologically and optically "clear." We do not routinely indicate chest tube placement for clinically evident empyema, where videoassisted surgery is performed as soon as possible after diagnosis.

In ME cases we have adopted the positioning of a small-bore wireguided chest drain as a first-instance treatment. We routinely perform video-assisted procedures for pleurodesis in all recurrent cases.

\section{Positioning Technique}

A $12 \mathrm{~F}$ small-bore multifenestrated wire-guided chest drain (Portex Seldinger Chest Drainage Kit; Smiths Medical, St Paul, Minn) was placed with the Seldinger technique in all cases at the patient's bed.

Patients were positioned in supine anti-Trendelenburg recumbence. Local anesthesia was provided using 100 to $200 \mathrm{mg}$ of lidocaine $(2 \%$ solution) and the drain was placed through the midclavicular line in the II-III intercostal space or on the IV, V, or VI intercostal space on the middle lateral line through the "triangle of safety."

The chest drain was secured to the skin with a $1-0$ or $0-0$ silk suture. The drainage was connected to a water seal system and aspiration was used in case of PNX if clinically needed. Antibiotic prophylaxis (intravenous amoxicillin-clavulanate $2.2 \mathrm{~g}$ or ceftriaxone $2.0 \mathrm{~g}$ in selected patients with anaphylaxis history for penicillin) was administered to all patients immediately before the procedure.

A chest $\mathrm{X}$-ray film was taken after each procedure to visualize the correct positioning of the drain in the pleural cavity.

Through the visual analogue scale (VAS), ${ }^{5}$ each patient was asked to indicate the pain experienced at the time of the drain insertion by marking a straight line ranging from $0 \mathrm{~mm}$ (no pain at all) to $100 \mathrm{~mm}$ (worst pain ever). Minor complications, major complications, and number of days of the drain in situ have also been recorded. Drain flushing was performed with $50 \mathrm{~mL}$ of saline solution in case blockage was suspected. The drain was removed when the amount of daily fluid was lower than $100 \mathrm{~mL}$ for NME/ME and when there was no evidence of air leak with a complete expansion of the lung without aspiration (maintained routinely for 3 days) in PNX cases.

Major complications of chest tube placement were defined as follows: organ penetration, heart and great vessel puncture, diaphragmatic perforation, intercostal vessel perforation, thoracic empyema, and any other complication that could not be included in any one of the previous categories but that caused prolonged hospitalization. Minor complications were wound infection, hypotension, and cutaneous bleeding. The failure of the drainage was evaluated with the presence of one of the following conditions: (1) inadequacy of placement or displacement of a chest tube that required its removal and replacement; (2) persistent PNX or NME/ME owing to blockage of drainage (despite drain flushing).

\section{Statistical Methodology}

Overall descriptive statistics were evaluated for all clinical and placement technique parameters. In particular, the absolute and relative frequency distributions of drainage failure and of the occurrence of major and minor complications at the time of the insertion itself were calculated. Measures of centrality and dispersion of the intensity of pain experienced by the patients and the number of days of drainage were calculated for each subgroup of patients with different indications for drainage. The risk of minor complications, of drainage failure, of prolonged stay of the drain in situ, and the risk of experiencing some pain at the time of insertion of the drain, associated to each indication for drainage, were evaluated by the Pearson $\chi^{2}$ statistics. The statistical software STATA/SE Release 10.0 (StataCorp LP, College Station, Tex) was used to perform all analyses. The level of significance was set at .05 .

\section{RESULTS}

Of the 1092 recruited subjects, $36.5 \%(\mathrm{n}=399)$ were treated for PNX, 29.7\% (n = 324) for ME, $24.9 \%$ $(\mathrm{n}=272)$ for NME, and $8.9 \%(\mathrm{n}=97)$ for empyema. In all of these cases the diagnosis of empyema was made pathologically via the determination of the $\mathrm{pH}$ of the drained fluid that appeared clear at optical inspection.

Repeated drainage was performed in 69 patients and a larger bore was used in 15 of them; the remaining patients were treated with a surgical approach or with radiologic (chest x-ray film) follow-up.

Descriptive statistics have been summarized in Table 1. Findings from the Pearson test of association are summarized in Table 2.

\section{Safety and Tolerability}

Major complications requiring a surgical approach (video-assisted thoracoscopy) occurred in only 1 patient with $\mathrm{ME}$ and consisted in the accidental loss of the wire

TABLE 1. Baseline clinical features of patients with pleuropulmonary diseases treated with small-bore drains

\begin{tabular}{lc}
\hline Age $($ mean years \pm SD) & $56 \pm 18$ \\
Gender $(\mathrm{n}(\%))$ & \\
Men & $418(38.7 \%)$ \\
Women & $674(61.3 \%)$ \\
Malignant effusion (n (\%)) & \\
Total & $\mathbf{3 2 4}(\mathbf{2 9 . 9 \% )}$ \\
Lung cancer & $122(37.7 \%)$ \\
Mesothelioma & $37(11.4 \%)$ \\
Genitourinarian tract neoplasm & $96(29.6 \%)$ \\
Hematologic neoplasm & $27(8.3 \%)$ \\
Gastroenteric neoplasm & $32(9.9 \%)$ \\
Other neoplasm & $10(3.1 \%)$ \\
Nonmalignant effusion (n (\%)) & \\
Total & $\mathbf{2 7 2}(\mathbf{2 4 . 9 \% )})$ \\
Cirrhosis & $64(23.5 \%)$ \\
Heart failure & $15(5.5 \%)$ \\
Postoperative (abdominal surgery) & $40(14.7 \%)$ \\
Kidney disease & $13(4.8 \%)$ \\
Parapneumonic effusion & $122(44.9 \%)$ \\
Other & $18(6.6 \%)$ \\
Pneumothorax (n (\%)) & \\
Total & $\mathbf{3 9 9}(\mathbf{3 6 . 5 \% )}$ \\
Primary & $285(71.4 \%)$ \\
Secondary & $114(28.6 \%)$ \\
Empyema (n (\%)) & \\
Total & $\mathbf{9 7}(\mathbf{8 . 9 \%})$ \\
\hline SD, Stan
\end{tabular}

$S D$, Standard deviation. 
TABLE 2. Primary clinical outcomes in the use of small-bore drains for the treatment of pleuro-pulmonary diseases

\begin{tabular}{|c|c|c|c|c|}
\hline & $\frac{\text { Pneumothorax }}{(n=399 ; 36.5 \%)}$ & $\frac{\text { Nonmalignant effusion }}{(\mathrm{n}=272 ; 24.9 \%)}$ & $\frac{\text { Malignant effusion }}{(\mathrm{n}=324 ; 29.7 \%)}$ & $\begin{array}{c}\text { Empyema } \\
(\mathrm{n}=97 ; 8.9 \%)\end{array}$ \\
\hline \multicolumn{5}{|l|}{ Drainage failures } \\
\hline $\mathrm{n}(\%)$ & $28(7 \%)$ & $21(7.7 \%)$ & $20(6.2 \%)$ & $72(74.2 \%)$ \\
\hline Relative risk of drainage failure $(95 \% \mathrm{CI})$ & $0.43 *(0.29 ; 0.64)$ & $0.53 *(0.39 ; 0.82)$ & $0.39 *(0.25 ; 0.62)$ & $10.70 *(8.29 ; 13.83)$ \\
\hline \multicolumn{5}{|l|}{ Minor complications } \\
\hline $\mathrm{n}(\%)$ & $18(4.5 \%)$ & $22(8.1 \%)$ & $13(4 \%)$ & $14(14.4 \%)$ \\
\hline Relative risk of minor complications $(95 \% \mathrm{CI})$ & $\mathbf{0 . 6 4}(0.38 ; 1.08)$ & $1.47(0.90 ; 2.41)$ & $0.57(0.32 ; 1.03)$ & $2.71 *(1.56 ; 4.70)$ \\
\hline \multicolumn{5}{|l|}{ Duration of drainage } \\
\hline Mean days \pm SD & $4.42 \pm 1.24$ & $5.73 \pm 1.55$ & $5.5 \pm 1.54$ & $7.6 \pm 1.53$ \\
\hline$>6$ days: $\mathrm{n}(\%)$ & $344(86.2 \%)$ & $143(52.6 \%)$ & $192(59.3 \%)$ & $5(5.2 \%)$ \\
\hline$\geq 6$ days: $\mathrm{n}(\%)$ & $55(13.8 \%)$ & $129(47.4 \%)$ & $132(40.7 \%)$ & $92(94.8 \%)$ \\
\hline Relative risk of prolonged drainage $(95 \% \mathrm{CI})$ & $0.27 *(0.21 ; 0.35)$ & $1.39 *(1.19 ; 1.63)$ & $1.13(0.96 ; 1.33)$ & $2.99 *(2.70 ; 3.31)$ \\
\hline \multicolumn{5}{|l|}{ Pain experience } \\
\hline Mean $\mathrm{mm} \pm \mathrm{SD}$ & $6.07 \pm 11.45$ & $4.87 \pm 10.29$ & $3.06 \pm 8.6$ & $3.25 \pm 8.39$ \\
\hline No pain: $\mathrm{n}(\%)$ & $245(61.4 \%)$ & $158(58.1 \%)$ & $259(79.9 \%)$ & $68(70.1 \%)$ \\
\hline Mild pain: $\mathrm{n}(\%)$ & $65(16.3 \%)$ & $71(26.1 \%)$ & $28(8.7 \%)$ & $20(20.6 \%)$ \\
\hline More severe pain: $\mathrm{n}(\%)$ & $89(22.3 \%)$ & $43(15.8 \%)$ & $37(11.4 \%)$ & $9(9.3 \%)$ \\
\hline Relative risk of experiencing some pain $(95 \% \mathrm{CI})$ & $1.29 *(1.09 ; 1.52)$ & $1.39 *(1.16 ; 1.65)$ & $0.52 *(0.41 ; 0.66)$ & $0.89(0.65 ; 1.23)$ \\
\hline
\end{tabular}

Relative and absolute frequencies, estimated relative risks and $95 \%$ confidence intervals from a cohort analysis. $C I$, Confidence intervals; $S D$, standard deviation. $*$ Evidence for a significant association $(P<.01)$.

guide into the pleural cavity at insertion. A radiogram is included as evidence (Figure 1). No hemothorax was reported, nor was abdominal/thoracic/mediastinal organ perforation or infection after the drain insertion procedure.

Minor complications occurred in 67 (6.14\%) patients. In particular, 18 events $(4.5 \%)$ occurred among those with PNX, 22 (8.1\%) among those with NME, 13 (4\%) were recorded in the ME group, and, last, $14(14.4 \%)$ cases with empyema were also observed. Evidence emerged for an association between the occurrence of minor complications and empyema, for which a relative risk of 2.71 , with a $95 \%$ con-

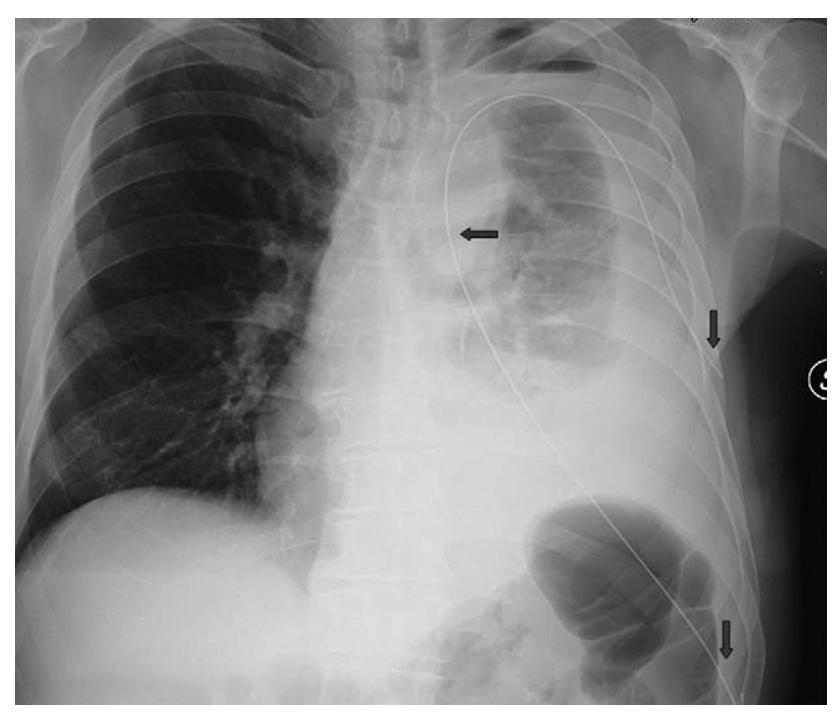

FIGURE 1. Accidental loss of a wire guide (gray indicators) into the pleural space. fidence interval ranging from 1.56 to 4.70 , was estimated. A list of all minor complications is provided in Table 3.

\section{Pain Experience}

With regard to the VAS scoring for pain at the time of insertion of the drain, and independently from the indication for the insertion, most patients experienced no pain $(66.9 \%)$ (Figure 2). Only 1 patient with NME (parapneumonic) assigned the maximum scoring to the VAS. In particular, the proportion of individuals who declared no pain were $245(61.4 \%)$ of those with PNX, $158(58.1 \%)$ of those with NME, $259(79.9 \%)$ with ME, and $68(70.1 \%)$ with empyema. The proportion of patients who reported having mild pain (VAS $=5 \mathrm{~mm}$ ) never raised above $26.1 \%$.

\section{Effectiveness}

Failure of the drainage procedure was experienced by 141 $(12.9 \%)$ individuals. The causes were dislodgment in 59 $(41.6 \%)$ and blockage or failure of resolution in 82 ( $58.4 \%$ of total failures) (Table 4$)$. When accidental removal or dislodgement (documented by chest radiography) was

TABLE 3. Minor complications in patients with pleuro-pulmonary diseases treated with small-bore drains

\begin{tabular}{lc}
\hline & $\mathbf{N}(\mathbf{\%})$ \\
\hline Total & 67 \\
Cough & $35(52.2 \%)$ \\
Hypotension & $13(19.4 \%)$ \\
Local bleeding & $10(14.9 \%)$ \\
Wound infection & $4(6 \%)$ \\
Surgical emphysema & $5(7.5 \%)$ \\
\hline
\end{tabular}




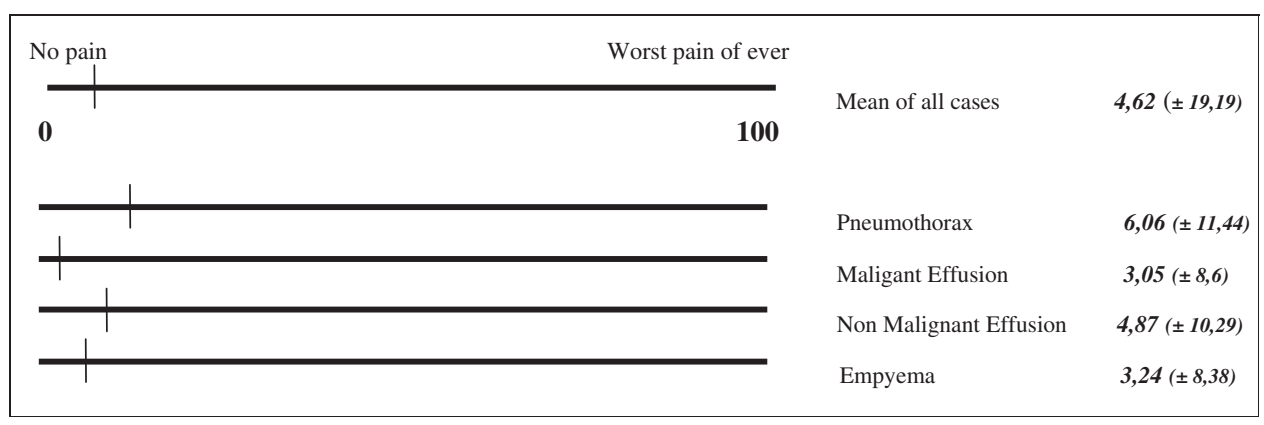

FIGURE 2. Distribution of pain score from $0 \mathrm{~mm}$ (no pain) to $100 \mathrm{~mm}$ (worst pain ever).

observed, the chest drains were replaced if the amount of visible pleural fluid at chest radiography was clinically significant. When blockage occurred, even after periodic flushing with saline solution $(n=43)$, an attempt to reinsert the drain was made. We therefore observed the presence of fibrin or blood coagula into the drain in almost all these cases.

Effectiveness of drainage was found to be associated with the indication for the procedure itself. In particular, a large proportion of patients with empyema experienced a failure with the small-bore drain. The absolute and relative frequency of failures for PNX, for NME/ME, and for empyema (pathologic) indications are reported in Table 4. From the analysis of exposure to the 4 different indications for drainage, it was estimated that patients with empyema (pathologic) were 10.7 times more at risk of experiencing a failure of the drain procedure than patients with any of the other indications. It was further estimated, with a $95 \%$ confidence, that this risk could be as low as 8.3 and as high as 13.8 .

\section{Duration of Drainage}

The observed mean duration of drainage was just under $4.5 \pm 1.25$ days for the PNX group, about $5.5 \pm 1.25$ days for the ME group, $5.75 \pm 1.5$ days for the NME group, and just over $7.5 \pm 1.5$ days for the empyema group. Moreover, it was observed that patients naturally clustered into 2 groups: those who kept the drain in situ for no less than 6 days and those who kept it for 6 days or more (details in Table 2). However, no patient with empyema kept the drain in place for less than 5 days. From this study it was observed that $86.7 \%(n=344)$ of subjects with PNX, 59.3\% $(n=192)$

TABLE 4. Absolute and relative frequencies for drainage failures by indication for drain insertion

\begin{tabular}{lcccc}
\hline & & \multicolumn{2}{c}{ Reason for drain removal } \\
\cline { 3 - 3 } & & Blockage & Dislodgment \\
Indication for drain insertion & $\mathbf{N}(\%)$ & $\mathbf{n}(\%)$ & & $\mathbf{n}(\%)$ \\
\hline Pneumothorax & $28(7)$ & $2(7)$ & & $26(93)$ \\
Nonmalignant effusion & $21(7.7)$ & $7(33)$ & $14(67)$ \\
Malignant effusion & $20(6.2)$ & $12(60)$ & $8(40)$ \\
Empyema & $72(74.2)$ & $61(85)$ & $11(15)$ \\
Grand total & $141(12.9)$ & $82(58)$ & $59(42)$ \\
\hline
\end{tabular}

of those with ME, and 52.6\% $(n=143)$ of those with NME kept the drain in place for less than 5 days. Only $5.2 \%$ of patients with empyema had it for such a short period of time. It was, in fact, estimated that the latter group had a risk for a prolonged drainage 3 times higher than any of the other 3 subpopulations ( $95 \%$ confidence intervals: $2.70 ; 3.31$ ).

\section{DISCUSSION}

Even if the daily activity and the international guidelines report a better tolerability and safety of small-bore wireguided chest drains in the treatment of NME/ME and PNX, the effectiveness of this approach is still debated and is not entirely evidence-based. In particular, the correct indications for the use of this type of drain inserted via the Seldinger technique are still a matter of discussion. In this context, in 2008 Davies, Merchant, and McGown ${ }^{4}$ drew the attention of pneumologists and thoracic surgeons to the lack of data from large-scale (randomized) clinical trials that supported the choice of small-bore (12F) wire-guided chest drains, instead of large-bore ones, for the treatment of various pleuropulmonary conditions. Davies' study, together with the publication of Horsley and associates, ${ }^{3}$ represents, to the best of our knowledge, the only report addressing, with a retrospective analysis of prospectically gathered data, the effectiveness and complication rates of small-bore wire-guided chest drains inserted percutaneously via the Seldinger technique. A significant ethical situation arose since the small-bore chest drains have been made available for clinical use. This is connected with the fact that the 2 systems (small-bore versus large-bore drains) imply a very different impact on the patients in terms of tolerability, pain, and safety (and probably costs, given the fact that lareg-bore drains are routinely positioned in surgical theaters, whereas small-bore wire-guided ones are placed at the patient's bedside). It is, thus, very difficult from the ethical standpoint to properly design and run a prospective randomized trial. Concerning safety, the life-threatening complications of large-bore intercostal chest drains are widely documented and described with rates of incidence from $0.2 \%$ to $6 \%{ }^{2,6-8}$ The complications include organ penetration leading to lung laceration, heart and great 
vessel puncture, diaphragmatic perforation, and spleen/liver injury. According to the relevant available literature, the frequency of these complications is notably reduced thanks to the use of the small-bore drains. ${ }^{6}$ As well, other complications like empyema, secondary to the insertion of pleural catheters, vary widely, with rates of up to $25 \%$. ${ }^{9,10}$ In the present study, there were no cases of empyema or drain site infections, and we speculate that this may be due to the definitely more rapid insertion of the small-bore wire-guided drains and to the minimal disruption of the chest wall as compared with blunt dissection. Antibiotic prophylaxis is normally used in both types of procedures.

We registered 1 major complication only, the accidental loss of the wire guide into the pleural cavity, and the rates of minor complications in absolute terms were acceptable if compared with the scarce data available in the literature.

With regard to pain and tolerability, the small-bore wireguided chest drains are generally considered more comfortable by the patients and induce less pain at the moment of insertion and afterward, compared with the large-bore ones. ${ }^{11}$ In line with the evidences reported by Horsley and colleagues ${ }^{3}$ and Davies, Gleeson, and Davies, ${ }^{1}$ our results showed that, independently from the indication the insertion, most of our patients had a significant absence of pain at the time of drain insertion.

An interesting point of open discussion remains the effectiveness of small-bore drains in PNX, NME/ME, and empyema. Our findings are in line with those of Horsley and colleagues, ${ }^{3}$ although they reported a higher rate of failure, blockage, or displacement: $37 \%$ of the total procedures, $7.5 \%$ of which represented by chest drain obstructions. Smaller figures were found in the article by Davies, Merchant, and McGown, ${ }^{4}$ who reported a $9 \%$ of blockage, a closer percentage to that observed in the present study $(12.9 \%)$. This dissimilarity stays dubious and probably is due to the frequency of drain flushing in the different series.

Similarly, the drain displacement rate was reported in the literature with a high variability (ranging from $6 \%-21 \%)^{3,4}$ and in the present study occurred in the $5.4 \%$ of cases. The $21 \%$ failure rate seems unacceptably high. We could infer that this may be due to different stitching techniques. Methods for securing chest drains vary between practitioners, and although various techniques have been described for largebore drains, ${ }^{12}$ the chosen strategies often depend on peer recommendation and local clinical practice rather than on randomized trial data.

Our experience also confirms the lower effectiveness of small-bore wire-guided drains at resolving empyema, with a limited success rate (24\%) and high propensity for blockage. Although these findings are not surprising, Horsley and associates $^{3}$ also suggested that small-bore wire-guided drains $(<20 \mathrm{~F})$ should not be routinely used in the treatment of empyema. This aspect is evident in the estimated number of days of drain in situ, which was significantly longer for patients with empyema than for those with other conditions. Finally, our results confirmed that the procedure-related pain is very low, regardless of the indication.

\section{Limitations}

This series is numerous and homogeneous. However, conclusions suffer from the fact that they are drawn on a retrospective analysis of prospectically gathered data. This should be kept in mind when revision of clinical procedures or guidelines is considered, based on these study results. Of course, there is an ethical problem in designing prospective randomized trials, given the very significant differences already highlighted in the preliminary observational experiences among the use of small- versus large- bore drains. We have excluded trauma patients from this study. Still, we consider this a significant limitation of our findings. We advocate for further research in this category of patients inasmuch as it would seem logical that in selected trauma cases the adoption of small-bore wire-guided chest drains may provide significant advantages (for example in the case of rib fractures without hemothorax).

\section{CONCLUSIONS}

Our data support the evidence that the use of small-bore wire-guided $12 \mathrm{~F}$ chest drains inserted via the percutaneous Seldinger technique is a safe and well-tolerated procedure, particularly in PNX, ME, and NME. In pathologically diagnosed empyema, however, we observed a low success rate and tendency to blockage, confirming the absence of indication for this condition. A larger base of evidence could be obtained with randomized trials, but these may prove difficult to design for ethical reasons.

\section{References}

1. Davies CW, Gleeson FV, Davies RJ. BTS guidelines for the management of pleural infection. Thorax. 2003;58(Suppl 2):ii18-28.

2. Henry M, Arnold T, Harvey J. BTS guidelines for the management of spontaneous pneumothorax. Thorax. 2003;58(Suppl 2):ii39-52.

3. Horsley A, Jones L, White J, Henry M. Efficacy and complications of small-bore, wire-guided chest drains. Chest. 2006;130:1857-63.

4. Davies HE, Merchant S, McGown A. A study of the complications of small bore "Seldinger" intercostal chest drains. Respirology. 2008;13:603-7.

5. Wewers ME, Lowe NK. A critical review of visual analogue scales in the measurement of clinical phenomena. Res Nurs Health. 1990;13:227-36.

6. Baldt MM, Bankier AA, Germann PS, Pöschl GP, Skrbensky GT, Herold CJ. Complications after emergency tube thoracostomy: assessment with CT. Radiology. 1995; 195:539-43.

7. Chan L, Reilly KM, Henderson C, Kahn F, Salluzzo RF. Complication rates of tube thoracostomy. Am J Emerg Med. 1997;15:368-70.

8. Etoch SW, Bar-Natan MF, Miller FB, Richardson JD. Tube thoracostomy. Factors related to complications. Arch Surg. 1995;130:521-5.

9. Eddy AC, Luna GK, Copass M. Empyema thoracis in patients undergoing emergent closed tube thoracostomy for thoracic trauma. Am J Surg. 1989;157:494-7.

10. Helling TS, Gyles NR 3rd, Eisenstein CL, Soracco CA. Complications following blunt and penetrating injuries in 216 victims of chest trauma requiring tube thoracostomy. J Trauma. 1989;29:1367-70.

11. Mair H, Kaczmarek I, Daebritz S. Modern drainage techniques include not only smaller drains for pain reduction. J Thorac Cardiovasc Surg. 2007;133:1124.

12. Rashid MA, Wikstrom T, Ortenwall P. A simple technique for anchoring chest tubes. Eur Respir J. 1998;12:958-9. 